\title{
Gestión urbana municipal a escala metropolitana: modelos en competencia ${ }^{1}$
}

\author{
Arturo Orellana², Pablo Allard ${ }^{3}$, Romina Néspolo ${ }^{4}$ y José Mercado 5
}

\begin{abstract}
RESUMEN
La pregunta que guía el desarrollo de este artículo es ¿qué se entiende por gestión urbana municipal?, particularmente para el caso de las áreas metropolitanas de Chile. Alcanzar esta respuesta supuso metodológicamente trabajar en construir un cierto consenso entre diferentes actores (sector público, sector privado, academia y sociedad civil) respecto a lo que debiera entenderse por gestión urbana municipal. Resuelto lo anterior, se determinó que conviven dentro del espacio metropolitano al menos tres modelos de gestión urbana municipal y que, ante la ausencia de un gobierno metropolitano como tal, cada municipio bajo un marco normativo y de manera autónoma, promueve o se aproxima a uno de estos modelos. Un primer modelo que denominaremos Prestador de Servicios, donde prima una concepción de la ciudadanía como cliente con predominio del mercado como agente transformador del espacio urbano, sin participación relevante de la sociedad civil. Un segundo modelo, el cual denominaremos Promotor, donde el municipio incide en las decisiones de inversión privadas directa o indirectamente, pero sin participación ciudadana relevante. $Y$, finalmente, un tercero que denominaremos Participativo, el cual apuesta a que la sociedad civil tenga un rol activo en los procesos de decisión en materia de gestión urbana municipal, restringiendo en forma importante la acción del mercado.
\end{abstract}

Palabras clave: Gestión urbana, municipios metropolitanos, gestión local, gobierno metropolitano.

\begin{abstract}
The triggering question that drives the development of this article is: what do we understand by municipal urban management?, that is, in close relation with Chile's metropolitan areas. In order to find a suitable answer to this quesion, we had to work on the methodological construction of some kind of consensus among different areas of interest (public sector, private sector, academic and civil society) to clearly define what municipal urban management is. Once the answer to the previuosly stated question was found, it was determined than inside the metropolitan space there interact three different models of municipal urban management and that due to the absence of a metropolitan government, as it were, each municipality fosters or gets close by to any of these models under a legal framework in an autonomous way. We will name the first model "Services", where citizens are predominantly clients and the service market acts as an active transformer of the urban space but without any relevant participation of the civil society. The second model will be that of "Promoter", where the municipality directly acts upon those decisions concerning private investments, either directly or indirectly, but without any significant role of the population. Last but not least, the third model will be named "Participative", which aims towards a rather active role of the population acting upon the decision making processes as far as the municipal urban management concerns, highly hindering the market's effect upon it.
\end{abstract}

Key words: urban management, metropolitan municipalities, local management, metropolitan government.

1. Proyecto "Indicadores de Gestión Urbana Municipal. La Situación de los Gobiernos Locales de las Áreas Metropolitanas frente al Desafío de la Planificación Urbana en la Actualidad" FONDECYT REGULAR 2008-2010, № 1085277. Artículo recibido el 25 de enero de 2011, aceptado el 29 de noviembre de 2011 y corregido el 5 de marzo de 2012.

2 Pontificia Universidad Católica de Chile (Chile). E-mail: amorella@uc.cl
3 Universidad del Desarrollo (Chile). E-mail: pallard@ udd.cl

4 Pontificia Universidad Católica de Chile (Chile). Email: rominanespolo@gmail.com

5 Pontificia Universidad Católica de Chile (Chile). Email: rominanespolo@gmail.com 
Las ciudades Latinoamericanas están sufriendo profundas transformaciones producto del fenómeno de la globalización, esto implica una fuerte reestructuración socioeconómica y la adopción y difusión de nuevas tecnologías de la información y de comunicación. Las consecuencias de este fenómeno van en directa relación con el crecimiento de las ciudades y las transformaciones territoriales de sus áreas locales (municipios o gobiernos locales). La nueva ciudad que comienza a estructurarse, posee dentro de su dinámica esencial procesos de reproducción urbana en los que cada rasgo y tendencia se redefinen y se transforman. Afectando a todas a las áreas metropolitanas y convirtiendo a la urbe en una ciudad fractal o dual donde el aumento de las desigualdades sociales, la segregación residencial, la delincuencia, aumento de la conflictividad social, caracterizarían de forma inexorable el paisaje social y territorial de la nueva ciudad (De Mattos, 2002).

Dentro de este significativo proceso social y urbano resulta de vital importancia el rol de los municipios como entes administradores del territorio. Como lo plantean Jordán et al. (2003), en el marco de la globalización y la descentralización es esencial una redefinición del rol y de la potencialidad de dichas entidades. La nueva economía urbana y la nueva estructura socioterritorial, forman parte de una realidad que impone a los administradores locales nuevos desafíos y tareas. Para las municipalidades, quienes gobiernan un territorio cada vez más complejo y dinámico, constituye toda una proeza administrar el espacio local y, con mayor razón, bajo el escenario de la globalización.

Bajo esta perspectiva es importante definir la realidad de los gestores locales en cuanto a sus atribuciones y limitaciones. Para entender el funcionamiento del gobierno local, municipio, resulta necesario remitirse a alguna definición general que ilustre sus funciones, deberes y derechos. En Chile, se concibe a las municipalidades como "corporaciones autónomas de derecho público, con personalidad jurídica y patrimonio propio, cuya finalidad es satisfacer las necesidades de la comunidad local y asegurar su participación en el progreso económico, social y cultural de las respectivas comunas" ${ }^{\prime \prime}$.

\footnotetext{
6 Según Artículo 1 de la Ley Orgánica Constitucional de Municipalidades $N^{\circ} 18.695,2001$
}

Por su parte, en el marco de los nuevos procesos de descentralización e independencia de los gobiernos locales, se plantea que los municipios son entidades de gobierno local autónomo en donde es importante promover el desarrollo económico y social, mejorar los servicios públicos y afianzar la gobernabilidad democrática. Bajo esta perspectiva, resulta de vital importancia el nivel de participación de los habitantes en cuanto a fortalecer la sociedad civil y su involucramiento en la toma de decisiones. En este sentido el Movimiento Municipalista latinoamericano plantea que la nueva gestión municipal latinoamericana es una manera abierta de gestionar el desarrollo, en donde las municipalidades deben concertarse con actores privados y ciudadanos para resolver los problemas constantes que presenta el desarrollo. De esta manera, la Unión Internacional de Autoridades Locales -IULA- plantea que la única manera de hacer políticas públicas efectivas es mediante la acción concertada de las autoridades públicas, la sociedad civil y el sector privado. La modernización del Estado pasa por el aprendizaje de estos nuevos modos de hacer política, con una ética renovada, con sistemas novedosos de rendición de cuentas y una ampliada transparencia de toda la gestión pública.

Considerando las nuevas perspectivas que hay en torno a los gobiernos locales, los nuevos desafíos que enfrenta dicha entidad dicen relación con las complejidades del territorio y el desarrollo de sus áreas locales, en cuanto a gobernarlas y gestionarlas. Entonces, frente a la temática de la descentralización y de la autonomía local ¿cómo los municipios enfrentan la nueva realidad territorial y qué herramientas poseen para gestionar el territorio frente al constante crecimiento y complejización de su espacio local? Es importante considerar dentro de este proceso que, cada vez más, los municipios adoptan mayores responsabilidades respecto de la calidad de vida de los habitantes. Los municipios chilenos se han transformado en el punto más cercano del Estado con la gente cuya responsabilidad es atender a ciudadanosclientes, los que cada vez son más exigentes en demandar mayor cantidad y mejores servicios e inclusive, con mayor exigencia en aquellas comunas donde la población es más pobre. 
De este modo, resulta importante analizar la gestión municipal desde una perspectiva amplia que involucre la complejización del territorio, la autonomía e independencia de la institución, los problemas que enfrenta diariamente y las fuertes diferencias que hay entre cada municipio.

\section{La historia reciente de los municipios en Chile}

Por casi un siglo, los municipios en Chile contaban con limitadas competencias y atribuciones para ejercer su gestión. Fue en 1976 que se realiza una importante reforma a la administración estatal, consistente en el traspaso de la responsabilidad de la educación y de la salud estatal desde el Gobierno central a los municipios, en un intento de dotarlos de autonomía financiera y administrativa (Chacón, 2007). Estas reformas de carácter descentralizador, fueron efectuadas en un contexto no democrático y con importantes carencias de recursos económicos y humanos. En primer lugar, desde septiembre de 1973 los alcaldes eran nombrados directamente por el Presidente de la República, cargo que ocupaba quien entonces había liderado el golpe militar, Augusto Pinochet Ugarte. Por otro lado, el país se encontraba en una crisis económica interna y ad portas de otra mundial, además de no contar con equipos de trabajo profesionales y técnicos capacitados para asumir estas nuevas tareas que se les demandaba.

De regreso a la democracia a partir de la década de 1990, se llevó a cabo una nueva reforma que restituyó el que las autoridades locales, alcaldes y concejales, deberían ser electos por sufragio universal y por un período de cuatro años ${ }^{7}$. Junto a lo anterior, se buscó resolver el problema de financiamiento de los municipios proveniente del Gobierno central, mediante la modificación de la Ley de Rentas Municipales, los impuestos territoriales a los bienes raíces y la creación del Fondo Común Municipal (FCM). Este instrumento se fundamenta en la redistribución de los ingresos propios municipales, permitiendo

7 Decreto Supremo de la Ley Orgánica de Municipalidades, 1992. equilibrar el sistema financiero municipal, con el objeto que los municipios pobres puedan contar con recursos mínimos para su desarrollo (Chacón, 2007). Finalizando la década de los noventa, sin la trascendencia que tuvieron las reformas anteriores, se aprueba en 1999 la nueva Ley Orgánica Constitucional de Municipalidades, la cual amplía las facultades de los municipios en materia de asistencia jurídica, seguridad ciudadana, fomento productivo y promoción de igualdad de derechos entre hombres y mujeres, además de entregar la función privativa de confeccionar el Plan Regulador Comunal.

En definitiva, todas las reformas emprendidas desde mediados de los años setenta, ponen de relieve un tema de fondo, referido a la necesidad de que progresivamente los municipios en Chile dejen de ser meros administradores locales, es decir, prestadores de servicios de carácter asistencial, promoviendo fuertemente la autonomía municipal, planificando territorialmente y con un fuerte componente de participación ciudadana no limitada a los procesos electorales. Pero ¿son suficientes las reformas municipales para que se logre este proceso del paso de administradores (prestadores de servicios) a la autonomía? Probablemente no, por ello se plantea que deben concurrir una serie de otros factores de tipo culturales para garantizar este paso.

\section{El municipio y la calidad de vida}

El traspaso de una mayor autonomía y responsabilidad hacia el municipio lo que busca en definitiva es mejorar la calidad de vida de los ciudadano/as. De esta forma las personas se relacionan directamente con el ente administrador, sin intermediarios y de acuerdo a la burocracia local, logrando, idealmente, una mayor eficacia y eficiencia a sus requerimientos. Para medir la calidad de vida existen ciertos indicadores ${ }^{8}$ los que se relacionan con:

a) las condiciones de la vivienda,

b) la situación de los servicios básicos anexos a la vivienda,

\footnotetext{
8 Definidos por la Secretaría Ministerial de Planificación y Coordinación, SERPLAC, 2005.
} 
c) la calidad del espacio público, y

d) el acceso a servicios de educación y salud

Todos estos indicadores y sus elementos asociados son en su mayoría entregados y administrados por las municipalidades, destinando para ello un porcentaje importante de su presupuesto anual. Un buen ejemplo que ilustra lo anterior es el destacar, que son las municipalidades los entes responsables por una parte de: la educación primaria y secundaria en un $60 \%$, también de la atención en salud primaria del $50 \%$ de la población comunal; por otra, además están vinculados al desarrollo urbano y a programas para combatir la pobreza, deben también atender las demandas de sus residentes en lo que respecta a la recolección de basura, la iluminación de las calles, construcción y mantención de espacios públicos y, a la vez, son también la principal "ventanilla" de acceso a los diversos servicios públicos.

Así, frente a los requerimientos de una población que aspira cada vez más a una mejor calidad de vida y reconoce en las autoridades locales al responsable de servirlo en ese propósito, los municipios deben organizarse y gestionar el territorio con recursos humanos calificados y provisto de la mejor tecnología disponible, aspectos que en muchos casos carecen en Chile gran parte de los municipios y más aún enfrentan una compleja realidad socioespacial en su territorio.

La construcción de un indicador de gestión municipal dice relación con la necesidad de administrar y desarrollar el territorio según las propias posibilidades que cada entidad posee, en virtud de las necesidades y limitantes como también de los factores positivos que el territorio les brinda. En este sentido, cobra especial relevancia el tema de la calidad de vida, como elemento esencial en la dirección del gobierno local, aspecto que se reforzaba y destacaba dentro del programa del gobierno Michelle Bachelet. En su discurso señalaba que el progreso económico y político no tiene sentido si las condiciones en las que vive la gente no mejoran. $Y$ afirmaba que el "desarrollo se mide por la capacidad de las personas para sentirse seguras en su barrio, vivir con dignidad en su casa, transportarse expeditamente a su trabajo y gozar de tiempo libre para la cultura, los deportes y la recreación" $" 9$

En definitiva, desarrollar una gestión eficiente permite a las municipalidades entregar una mejor calidad de vida a sus residentes, conforme el hecho que es la entidad pública más cercana a la realidad cotidiana de la gente. En dicho propósito, la administración local tiene el desafío de orientar su accionar hacia la búsqueda de respuestas y soluciones a las problemáticas de diversa índole en el espacio local donde se conjugan complejidades sociales y dinámicas económicas particulares a cada realidad dentro de un mismo territorio metropolitano.

\section{Las ganancias locales de la buena gestión municipal}

La buena gestión municipal genera una serie de consecuencias positivas en la administración municipal; rapidez y eficiencia en los trámites, provechosa utilización de los recursos y la posibilidad de producir proyectos de desarrollo comunal. Por el contrario, las burocracias e ineficiencias que, en ocasiones, presentan las municipalidades, perjudica el progreso de estas en cuanto al desincentivo que genera la lentitud de los trámites y permisos, tanto para los ciudadanos como para los proyectos privados que buscan construir o instalarse en la comuna ${ }^{10}$.

La buena gestión, por lo demás, dice relación con la afinidad de los municipios con los residentes. La participación ciudadana genera un equilibrio entre las demandas ciudadanas y las políticas urbanas, lo que garantiza la gobernabilidad. La difusión de los proyectos permite una comprensión global, integrando otras necesidades, creando nuevas formas de aprendizaje y resolución de los

9 Gobierno de Chile, Programa de Gobierno 20062010.

10 En la revista Fundamenta de la Cámara Chilena de la Construcción, se plantea que las ineficiencias causan desincentivo en el desarrollo de proyectos inmobiliarios. A raíz de esto los inversionistas pueden preferir otras localizaciones que presenten menos trabas para la implementación de sus proyectos. Por lo demás, las demoras en los permisos de construcción retrasa la percepción de los ingresos municipales (Fundamenta, 2004, N 18) 
problemas (Bresciani, 2006). De esta forma se evitan los posibles conflictos por el desconocimiento y rechazo de proyectos que no fueron consultados oportunamente. $Y$ se recogen las demandas colectivas de desarrollo comunal, alcanzando principios democráticos en las políticas públicas. Fundamentales para las buenas prácticas municipales.

\section{La gobernabilidad en las zonas metropolitanas y las gobernanzas locales}

La particularidad que agregan las zonas metropolitanas, subyace al hecho que tienden a una ruptura de la estructura espacial tradicional compacta y con centro único hacia una difusa y con más de un núcleo, una dualidad de la provisión y calidad de los servicios fuertemente correlacionado con la capacidad de pago de la población residente, así como una relativa carencia de infraestructura y equipamiento social en zonas (a escala municipal, algunas veces) donde se concentran con altas densidades población de bajos ingresos, principalmente en los municipios de la periferia. La gobernabilidad entonces pasa ser una condición preponderante para asegurar la estabilidad política, social y económica en pro del desarrollo y mayor competitividad de las metrópolis de modo de insertarse con mayor éxito en la red de ciudades globales.

La gobernabilidad como la definen Arbòs y Giner (1993), es un ejercicio que combina la legitimidad y la eficacia, donde la primera condición revela la admisión de normas y procedimientos aceptados socialmente, mientras la segunda apela a la capacidad de responder adecuadamente a las demandas sociales. Sobre el primer aspecto, es preciso entender que la legitimidad de los procesos que sostienen el principio de un buen gobierno sobre un territorio, si antes se contemplaba que debiera ser gestionado básicamente por un Estado centralizado, ahora se presupone la presencia de un Estado descentralizado y con la ascendente participación de las administraciones locales y, sobre todo de la empresa privada (De Mattos y Riffo, 2005).

En alguna medida, se establece entonces una jerarquía urbana y territorial diferente que da cuenta de una gobernabilidad en el plano metropolitano, la cual se revela desde la capacidad de influir que tiene cada municipio en este ámbito, como resultado de un cambio de paradigmas en términos de proximidad y de verticalidad. Esta situación surge no solo derivada de las actividades productivas, sino también de las funciones superiores relacionadas con la dirección, el control y el liderazgo político que se sostiene en el territorio (Camagni, 2005). Así entonces, las estrategias que predominan en el desarrollo de las zonas metropolitanas, como lo señala Le Gales (2002), distinguen cuando menos dos formas de concebir la governance urbana que se instala desde plataformas de poder $y$ también de contrapoder, como son:

- Un modo empresarial en donde la ciudad se organiza como un actor colectivo a fin de privilegiar su crecimiento económico, o

- Una modalidad que busca conciliar crecimiento económico con preservación de la cohesión social.

Ambas estrategias suponen igualmente la necesidad de que el Estado juegue un rol importante en la gobernanza que rige las actuaciones que dinamizan y posibilitan el desarrollo armónico de los territorios, sean desde su estructura política administrativa local, metropolitana o regional. En consideración a estos planteamientos, se puede sostener que una adecuada medida de la influencia que puede ejercer el Estado está dada por tres factores: las características de su configuración socioespacial, la autonomía sobre las decisiones de inversión pública efectiva y el nivel de inserción del sector privado en el territorio. Cuando existe un fuerte proceso de concentración de directivos profesionales a escala municipal, aquella con mayor grado de influencia política y económica (directivos, empresarios, políticos, profesionales, científicos), no solo se acentúa una mayor asimetría entre la realidad local y la metropolitana, sino que el interés público y el privado encuentran menor oposición para dialogar y transformar el espacio urbano, sobre todo más allá de sus límites político-administrativos de competencia (Orellana, 2005).

Cabe preguntarse entonces, si la configuración espacial resultante establece un posicionamiento de los municipios sobre el espa- 
cio metropolitano, es decir, un número menor de municipios logra establecer un mayor control sobre los procesos de toma decisiones que afectan las transformaciones urbanas y territoriales a escala metropolitana. Desde la perspectiva teórica, la condición de homogeneización a escala comunal y de marcada heterogeneidad intercomunal que presentan gran parte de las metrópolis latinoamericanas, incluidas las chilenas (Gran Santiago y Gran Concepción o Pencopolitano, en menor medida Gran Valparaíso), admite que se cumpla lo que señala Sánchez (1991) de que la articulación del espacio es función básica del modelo de producción-gestiónapropiación del valor excedente propio de la formación social vigente en cada momento a partir del espacio social previo -que a su vez comporta un espacio físico genealógicamente considerado. Esto significa, que los que ejercen el poder de la misma forma que intentan adecuar la estructura social a sus objetivos, lo harán con el espacio para condicionar sus usos en función de sus intereses que alcanzan una dimensión más allá de lo local.

Atendiendo la definición que acuña la Real Academia Española para definir la gobernanza como ente orgánico que actúa sobre el territorio, esta la define como "la manera de gobernar que se propone como objetivo el logro de un desarrollo económico, social e institucional duradero, promoviendo un sano equilibrio entre el Estado, la sociedad civil y el mercado de la economía". Se trata de un nuevo estilo de gobierno, donde interactúa el Estado con actores no gubernamentales al interior de redes decisionales mixtas donde se confrontan el interés público y el privado. Se concibe por la gobernanza como una modalidad distinta de coordinación de las acciones individuales, entendidas como formas primarias de construcción del orden social (Mayntz, 1998).

Las interrogantes que se proponen, obligan a revisar la participación en las decisiones públicas a escala regional y local en ausencia de gobiernos metropolitanos, considerando que el rol del Estado debiera minimizar los desequilibrios que se generan a partir de la configuración socioespacial resultante. Lo anterior, considerando la premisa que para los casos de estudios escogidos, se trata de territorios que no tienen una institucionalidad de gobierno acorde a su escala funcional, aunque está política y administrativamente inserta como parte de la Región Metropolitana, donde es gobernada por un intendente que es el representante del Gobierno central, acompañada en las decisiones por un Consejo Regional cuyos miembros tampoco son elegidos directamente por la ciudadanía y por una estructura de instituciones (secretarías ministeriales y direcciones de servicios) que responden política y administrativamente a los lineamientos impuestos desde las autoridades adscritas al Gobierno central ${ }^{11}$.

La forma en que se expresa la mayor o menor competitividad entre municipios en una escala metropolitana, va de la mano del carácter de las acciones que, desde el ámbito de la gestión local, se ejercen con influencia y en una perspectiva del desarrollo urbano y territorial muy ligada a los intereses del perfil socioterritorial de su población predominante. Sin embargo, en una aproximación más integral, se puede plantear que son tres los factores a escala local que son determinantes en la gobernabilidad metropolitana, a saber:

- Autonomía territorial, entendiendo por ello la capacidad del gobierno municipal de tener un mayor control de los procesos de decisión sobre las actuaciones urbanas y territoriales que ocurren en su comuna. Así entonces, una comuna podrá carecer de cierta autonomía territorial, tanto por sostener en su territorio el despliegue de grandes infraestructuras públicas y privadas que externalizan gran parte de las decisiones, o ya sea porque dispongan de suelo urbanizable, condición propia de las comunas periféricas.

- Capacidades endógenas, entendiendo por ello la existencia de una población residente con capacidades directivas y profesionales que fortalezcan la red de influencia y de control efectivo sobre la gestión local, así como para potenciar la atracción del territorio comunal para la inversión privada a través de proyectos más en sintonía con las demandas de la comunidad social y política residente.

11 Sobre las competencias y facultades de los gobiernos regionales y sus autoridades, se puede revisar la Ley Orgánica Constitucional de Gobierno y Administración Regional № 19.175 
- Disponibilidad de recursos, entendiendo por ello la disponibilidad de recursos económicos y técnicos (personal municipal) que permitan llevar a cabo una gestión local con los mayores estándares de calidad posibles, así como influir significativamente en los procesos de actuación urbano y territorial dentro de la comuna.

Estos tres factores que definen el grado de influencia en la gobernabilidad metropolitana de los municipios (Fuentes et al., 2007)12. En términos exploratorios, se puede considerar que una mayor tendencia a la externalización, significa que son factores externos los que resultan más determinantes en los procesos urbanos y territoriales que marcan el desarrollo local y metropolitano. Así entonces, una menor capacidad en cada uno de los tres factores expuestos, implica que la gestión del municipio resulta menos eficaz para influir más sustancialmente en la dinámica socioterritorial local y, al mismo tiempo, se constata una menor competitividad intracomunal para incidir en la estructura de poder que gobierna a escala metropolitana.

En definitiva, un municipio tendrá mayor capacidad de incidir en la gobernabilidad metropolitana, cuando sostenga una importante autonomía territorial, muestre capacidades endógenas muy por sobre la media comunal y cuente con un disponibilidad de recursos suficientes en términos económicos y profesionales para una satisfactoria gestión municipal.

\section{Marco metodológico ${ }^{13}$}

\section{Diseño de la muestra}

La estrategia metodológica utilizada en esta investigación ha sido de carácter exploratorio-descriptivo enmarcándose en un enfoque metodológico de corte cualitativo ${ }^{14}$. Se trabaja tanto con datos "primarios" como "secundarios". Para el levantamiento de los datos primarios se determinó un diseño muestral intencional según "sujetos tipo". A partir de su relación con la gestión urbana municipal. Los datos secundarios, que serán útiles para complementar el análisis de los datos primarios, se remiten a la revisión de la discusión cubierta por la prensa escrita.

El universo está compuesto por actores relevantes en materias de gestión urbana a escala municipal y urbana. Para ello se identificaron cuatro categorías:

- Académicos: Docentes e investigadores.

- Empresarial: Inversionistas privados e inmobiliarios.

- Sociedad Civil: Promotores y defensores de la participación ciudadana.

- Gobierno: Directivos del sector público.

12 Esta trilogía de factores ya fue planteada en una investigación previa cuyos resultados principales están publicados en el artículo señalado.

13 En lo que respecta a aspectos metodológicos y de edición queremos destacar los aportes de Daisy Margarit, doctora en Sociología, encargada de Investigación de la Escuela de Trabajo Social de la Universidad Jesuita Alberto Hurtado.

14 Se ha optado por un estudio de carácter cualitativo por cuanto se estima como el más apropiado para abordar fenómenos que no han sido cuantificables por la naturaleza del problema o cuando el investigador supone que la situación ha sido concebida de manera restrictiva y el tema requiere ser reexaminado. Los resultados de la investigación cualitativa inspiran y guían la práctica, dictan intervenciones y producen políticas sociales. Los métodos cualitativos pueden ser empleados confiable y válidamente para evaluar, para documentar mecanismos de cambio microanalíticamente y para registrar transformaciones estructurales de la sociedad (Morse, 2005d:583). Mediante la investigación microanalítica se exploran, evalúan, diagnostican, mecanismos, comportamientos, sistemas u organizaciones, se estudian problemas, procesos, interacciones e indicadores o situaciones (Morse, 2004b:151). 
Cuadro $\mathrm{N}^{\circ} 1$

Mapa de actores relevantes en gestión urbana en Chile

\begin{tabular}{|c|c|c|c|}
\hline $\begin{array}{l}\text { Categoría de } \\
\text { actores }\end{array}$ & $\begin{array}{l}\text { Descripción de su relación } \\
\text { con el tema de estudio }\end{array}$ & $\begin{array}{l}\text { Nivel de vínculo en la gestión } \\
\text { urbana metropolitana }\end{array}$ & $\begin{array}{l}\mathrm{N}^{\mathrm{o}} \text { de } \\
\text { participantes }\end{array}$ \\
\hline $\begin{array}{l}\text { Académicos: } \\
\text { Docentes e } \\
\text { investigadores }\end{array}$ & $\begin{array}{l}\text { Han desarrollado investi- } \\
\text { gaciones y han formulado } \\
\text { propuestas de política pú- } \\
\text { blica en materia gestión } \\
\text { municipal, relativas a los } \\
\text { ámbitos que tiene repercu- } \\
\text { sión en las transformacio- } \\
\text { nes urbanas y territoriales } \\
\text { del espacio local y metro- } \\
\text { politano en Chile en los } \\
\text { últimos } 20 \text { años. }\end{array}$ & $\begin{array}{l}\text { Asesoran a entidades del Estado } \\
\text { en materia de política pública y } \\
\text { sus opiniones son consideradas } \\
\text { por directivos que toman de } \\
\text { decisiones, sean estos públicos } \\
\text { o privados. }\end{array}$ & 8 \\
\hline $\begin{array}{l}\text { Empresarial: } \\
\text { Inversionistas } \\
\text { privados e } \\
\text { inmobiliarios }\end{array}$ & $\begin{array}{l}\text { Segmento constituido por } \\
\text { empresarios y altos directi- } \\
\text { vos privados (gerentes y/o } \\
\text { representantes gremiales) } \\
\text { ligados a proyectos de in- } \\
\text { versión de alto impacto en } \\
\text { la transformación urbana y } \\
\text { territorial de la metrópolis. }\end{array}$ & $\begin{array}{l}\text { Básicamente, a través de pro- } \\
\text { yectos privados como infraes- } \\
\text { tructura asociada a la industria } \\
\text { del retail, proyectos inmobilia- } \\
\text { rios para la vivienda e infraes- } \\
\text { tructura concesionada. }\end{array}$ & 8 \\
\hline $\begin{array}{l}\text { Sociedad Civil: } \\
\text { Promotores y } \\
\text { defensores de } \\
\text { la participación } \\
\text { ciudadana }\end{array}$ & $\begin{array}{l}\text { Segmento constituido por } \\
\text { representantes de movi- } \\
\text { mientos ciudadanos, al- } \\
\text { gunas de perfil ONG, que } \\
\text { apelan a una mayor par- } \\
\text { ticipación ciudadana en } \\
\text { las decisiones y procesos } \\
\text { de política pública que se } \\
\text { materializan en proyectos } \\
\text { de inversión, así como del } \\
\text { sector privado que impac- } \\
\text { ten sobre el desarrollo ur- } \\
\text { bano y la sustentabilidad } \\
\text { ambiental. }\end{array}$ & $\begin{array}{l}\text { Promueven acciones de protesta } \\
\text { que trasciendan a los medios } \\
\text { de comunicación y acciones } \\
\text { legales para entorpecer o lograr } \\
\text { mitigar los impactos de proyec- } \\
\text { tos públicos o privados de alto } \\
\text { impacto. }\end{array}$ & 8 \\
\hline $\begin{array}{l}\text { Gobierno: } \\
\text { Directivos del } \\
\text { sector público }\end{array}$ & $\begin{array}{l}\text { Segmento constituido por } \\
\text { funcionarios del Estado que } \\
\text { ocupan cargos directivos, } \\
\text { tanto a nivel central, regio- } \\
\text { nal y municipal, con res- } \\
\text { ponsabilidad directa en las } \\
\text { decisiones en materia de } \\
\text { inversión vía proyectos de } \\
\text { infraestructura y vivienda, } \\
\text { así como en la formulación } \\
\text { de planes reguladores y } \\
\text { normativas en materia de } \\
\text { uso de suelo. }\end{array}$ & $\begin{array}{l}\text { Deciden sobre la naturaleza } \\
\text { y focalización de la inversión } \\
\text { pública, así como también pro- } \\
\text { mueven cambios en el marco } \\
\text { regulatorio y normativo. }\end{array}$ & 7 \\
\hline
\end{tabular}

Fuente: Elaboración propia. 
A partir de cada una de estas categorías, se procedió a la segunda etapa de la estrategia metodológica, cuyo objetivo era recoger las diversas opiniones y develar los juicios, en el marco de un debate sobre ¿qué entendemos por gestión urbana para la realidad chilena? Para ello fue necesario realizar un mapa de posibles actores relevantes en la materia y representantes de cada categoría, para luego proceder a contactarlos. En el Cuadro $N^{\circ} 1$, se describen cada grupo de actores y su nivel de vinculación con el tema de estudio.

Una vez identificados los personeros y convocados a participar de esta investigación, se entró a la tercera etapa de la estrategia metodológica, para lo cual se utilizó la técnica de focus group. Se privilegió esta técnica por sobre las entrevistas individuales, por cuanto esta técnica permite adentrarse en el cómo los individuos participantes forman un esquema o perspectiva de un tema o problema, aquí la unidad de análisis es el grupo (lo que expresa y construye) (Hernández et al., 1997).

En total se realizaron cuatro sesiones de focus group. Cada sesión estuvo integrada por los actores de la misma categoría, es decir no se mezclaron los actores. Esto respondió a una decisión metodológica que buscaba no permear las opiniones entre grupos, ya que la unidad de análisis, como se dijo anteriormente, está en el grupo, para nuestro caso en la categoría que los identifica. Cada grupo estuvo constituido por un número que varió entre 7 y 8 invitados más todo el equipo de investigación. Cada sesión tuvo una duración promedio de cuatro horas de trabajo. La guía de tópicos que ordenó las sesiones consideró las siguientes preguntas:

a) ¿Cuándo cree usted que un municipio realiza una buena gestión urbana?

b) ¿De qué factores depende la buena gestión urbana de un municipio?

c) ¿Cuáles son factores atribuibles al municipio y cuáles a agentes externos?

d) ¿Qué se necesita para mejorar la gestión del municipio?

e) ¿Qué herramientas e instrumentos serían necesarios para mejorarlo?

f) ¿Con qué parámetros mediría usted la gestión del municipio?
La cuarta y última etapa de la estrategia metodológica de la investigación, estuvo centrada en el análisis de las opiniones recogidas en casa sesión.

La información es analizada mediante la técnica de análisis de contenido. El análisis de contenido como aproximación empírica se desarrolla metodológicamente controlando los textos al interior de sus contextos de comunicación, siguiendo reglas analíticas de contenido y modelos paso a paso, sin una cuantificación de por medio. Dicho análisis permite (i) denotar tanto el contenido manifiesto como el contenido latente de los datos analizados, y (ii) reelaborar los datos brutos, ya sea simplemente aglutinándolos en clusters o conjuntos homogéneos que agrupen material de similar sentido a través de pasos sucesivos hasta llegar a la conceptualización o regla descriptiva que justifique su agrupamiento o bien, integrando dichos datos a interpretaciones o abstracciones de mayor nivel que permitan. Así, en el transcurso del análisis que se lleva a cabo se obtiene mayor profundidad y riqueza analítica y, por último, se genera información válida y confiable, comprensible intersubjetivamente, que permita comparar los resultados con otras investigaciones.

A partir de este análisis, en primera instancia nos permite concluir que no solo se constata la ausencia de una definición consensuada sobre lo que se entiende por "gestión urbana", sino que también, se reconoce que cada municipio perteneciente a un área metropolitana sostiene un enfoque diferente sobre los alcances de su tarea como gestor político y administrativo del territorio comunal. Ambas constataciones son parte de los análisis de resultados que entrega este artículo.

\section{Análisis acerca del dilema sobre qué es gestión urbana municipal}

Los resultados obtenidos en los cuatro focus group aplicados, permitió establecer que había ciertas funciones que, conforme a los planteamientos entregados por los participantes en cada uno de los grupos, eran inherentes a una buena gestión urbana de los 
municipios. El Cuadro № 2 sintetiza aquellas funciones que alcanzaron más consenso en el debate al interior de cada grupo, considerando que fueron señaladas en forma recurrente para distinguir una buena gestión urbana desde un gobierno local. Muestra una matriz que en sus filas contiene todas las funciones señaladas, mientras que en las columnas están identificados cada uno de los grupos de referencia.

Cuadro $\mathrm{N}^{\circ} 2$

Matriz de representación de funciones propias de una buena gestión urbana

\begin{tabular}{|c|c|c|c|c|}
\hline & Académica & Empresarial & $\begin{array}{l}\text { Sociedad } \\
\text { Civil }\end{array}$ & Gobierno \\
\hline $\begin{array}{l}\text { Gestor o promotor de proyectos } \\
\text { emblemáticos para la comuna. }\end{array}$ & $x$ & & $x$ & $x$ \\
\hline $\begin{array}{l}\text { Articulación con otros actores } \\
\text { para la gestión del territorio } \\
\text { comunal. }\end{array}$ & $x$ & & $x$ & \\
\hline $\begin{array}{l}\text { Calidad y eficiencia en la } \\
\text { prestación de servicios a la } \\
\text { comunidad. }\end{array}$ & $x$ & $x$ & & $x$ \\
\hline $\begin{array}{l}\text { Cuando no interfiere en la } \\
\text { aprobación de los proyectos } \\
\text { privados. }\end{array}$ & & $x$ & & \\
\hline $\begin{array}{l}\text { Cuando aporta a la ciudad } \\
\text { acogiendo usos no deseados. }\end{array}$ & & $x$ & $x$ & \\
\hline $\begin{array}{l}\text { Cuando existe una visión de } \\
\text { futuro y un plan estratégico para } \\
\text { lograrlo. }\end{array}$ & $x$ & $x$ & $x$ & $X$ \\
\hline $\begin{array}{l}\text { No se modifica constantemente } \\
\text { las reglas del juego (PRC y otras } \\
\text { normativas). }\end{array}$ & & & $x$ & \\
\hline $\begin{array}{l}\text { Cuando incorpora en los } \\
\text { procesos de planificación y } \\
\text { gestión a la sociedad civil. }\end{array}$ & $x$ & & $x$ & \\
\hline $\begin{array}{l}\text { Cuando es capaz de generar } \\
\text { proyectos que generan un } \\
\text { redistribución de la renta } \\
\text { urbana. }\end{array}$ & & & $x$ & \\
\hline $\begin{array}{l}\text { Asociativa en iniciativas con } \\
\text { otros municipios y/o de escala } \\
\text { metropolitana }\end{array}$ & & & $x$ & $x$ \\
\hline
\end{tabular}

Fuente: Elaboración propia. 
Frente a la interrogante planteada sobre cómo saber que un municipio realiza una buena gestión urbana, las funciones expresan visiones que al interior y entre grupos dan cuenta de dimensiones diferentes de la tarea, es decir, comprometen aproximaciones disímiles sobre el rol que debe jugar un municipio en materia de gestión urbana y territorial. Así es posible entonces navegar dentro de un sinnúmero de definiciones que ponen hincapié en aspectos diversos, pero también relevantes, tales como: capacidad de articularse con otros actores locales al gestionar, emprender proyectos emblemáticos que denoten inversión pública y privada, mejoramiento en la provisión de servicios de cargo municipal (aseo y ornato, trámites y permisos por ventanilla, entre otros), sostener una visión de futuro en su quehacer, genera redistribución de rentas urbanas entre residentes o promueve la participación ciudadana en los procesos de decisión. Cada una de estas funciones señaladas, por lo general, sostienen adherentes en más de uno de los cuatro grupos de referencia, a excepción cuando solo aquellos representantes ligados al mundo empresarial definen como principio de una buena gestión urbana que el municipio no intervenga en la aprobación de proyectos urbanos y, en contrapartida, cuando los representantes de la sociedad civil se inclinan por instrumentos normativos menos flexibles en materia de regulación urbana o que promuevan una redistribución de la renta urbana.

La complejidad que reviste arribar a una definición que integre la totalidad de las funciones declaradas por los grupos de referencia, se presenta por el hecho que requiere incorporar a la amplia tarea de ejecución y administración de bienes públicos, no solo responsabilidades en materia de la provisión de infraestructuras diversas, sino todo aquello que es parte de un sinnúmero de demandas ciudadanas y/o que afectan la calidad de vida de las personas en la comuna ${ }^{15}$. Así entonces,

15 En esta etapa de la reflexión queremos agradecer los comentarios y aportes entregados por el Phd. y sociólogo Germán Correa, ex Ministro de Transporte y del Interior de Chile, el cual durante el período de esta investigación ocupaba el cargo de Secretario Ejecutivo del Comité Interministerial para la Ciudad y el Territorio, Ministerio de Vivienda y Urbanismo. se requiere precisar muy bien conceptualmente lo que se desea medir en esto de la "gestión urbana", porque una cosa es la gestión municipal en sí, otra diferente es la "gestión urbana" de un municipio. Una definición posible, a la luz de las diversas funciones que conlleva esta tarea, es considerar que esta se refiere a "aquellas decisiones que desde el municipio, en forma directa o indirecta, transforman el espacio local e impactan en la calidad de vida de sus residentes y usuarios ${ }^{16}$. . Ciertamente, la definición admite la existencia de más de un modelo de gestión urbana municipal, lo que implica que puede haber más o menos mercado, más o menos participación ciudadana, más o menos rigidez en materia de regulación, más o menos asociativa intra o intermunicipal, en otros factores.

\section{Modelos de gestión urbana municipal}

La diferencia de los expertos en la definición del papel que los gobiernos locales deben jugar en materia de gestión urbana, más que originada en lo que se entiende o no por "gestión urbana" está mediada por la aproximación al rol del Estado que estos declaran y, más específicamente, en las distintas concepciones que sostienen respecto a la gobernabilidad de los territorios y el papel de la sociedad civil en dicha tarea. Por tal motivo, lo que se expresa en las posiciones y debates que surgieron de los focus group, no es más que una constatación de que existen al menos tres modelos de gestión urbana municipal en disputa en los espacios metropolitanos para el caso chileno: municipio prestador de servicios, municipio promotor y municipio participativo. Para entender bien los alcances de esta tipología, podemos declarar que:

- Municipio prestador de servicios: será aquel cuyas acciones estén única o principalmente orientadas a la tarea de responder en forma eficaz y eficiente a las demandas de su población residente

\footnotetext{
16 Los municipios deben dar respuesta a las demandas por una mejor calidad de vida no solo de su población residente, dado que muchos municipios pueden ser receptores de una población flotante por razones laborales, educativas o turísticas, particularmente los municipios que son parte de áreas metropolitanas.
} 
o usuaria, desde la perspectiva de que el municipio tiene clientes a los cuales debe prestar servicios de calidad para garantizar la continuidad del mandato. Adicionalmente, se puede suponer que el estilo de gestión será intentar situar las acciones en el ámbito estrictamente de sus atribuciones, impulsando posiblemente más consultas que procesos participativos sobre la base de opciones fundamentalmente decididas desde la administración local.

- Municipio promotor: es aquel que junto con intentar entregar servicios de calidad a la ciudadanía y sus usuarios preferentemente con un enfoque de proveedor-cliente, tendrá la tendencia de desarrollar proyectos con sentido público (básicamente mejoras en espacio público y equipamiento comunal), eventualmente asociados con privados bajo entidades corporativas, con el objeto de influir en el desarrollo urbano y territorial para que la iniciativa privada vaya en armonía con la visión del municipio. Posiblemente, bajo este enfoque de gobierno local, se generen algunos procesos participativos, pero muy acotados y circunscritos a iniciativas estrictamente ligadas a la legalidad vigente o con efectos electorales.

- Municipio participativo: supone un enfoque de gobierno municipal donde se asume que la tarea de decidir sobre la orientación de la inversión pública sobre el territorio comunal, debe ser establecida mayoritariamente bottom-up, es decir, reforzando a una ciudadanía organizada y empoderada para tomar decisiones que luego serán gestionadas y administradas por el gobierno local. Este enfoque que considera al residente o usuario como un ciudadano en un sentido político, supone también que es la manera más democrática y a la vez más eficiente para dar respuestas satisfactorias a las demandas de la ciudadanía. Esta práctica también será utilizada frente a la necesidad de decidir o no cursar autorizaciones para ciertos desarrollos privados. Finalmente, posiblemente un municipio bajo esta perspectiva de gobierno tienda a colocar en su agenda de prioridades materias que escapan a las atribuciones municipales como tareas.
Estos tres modelos de gestión municipal, en algunas ocasiones resultan ser producto de un sello personalista de un alcalde de turno o de un movimiento político que toma el control del gobierno local. Sin embargo, también suele suceder que los municipios se ven arrastrados a gestionar de un modo determinado por factores que escapan a su gobernabilidad y lo obliga a externalizar parte significativa de las decisiones que tienen implicancias en la transformación del espacio local, como son la falta de autonomía territorial, débiles capacidades endógenas y/o escasez de recursos.

\section{Conclusiones}

En los espacios metropolitanos, bajo ausencia de un gobierno a escala ciudad, más que supeditado a una autoridad regional o central, la gestión urbana municipal se expresa al menos bajo tres modelos: prestador de servicios, promotor o participativo. Independiente del modelo de gestión urbana que adopten, lo concreto es que todos los municipios se ven obligados a competir por hacer de sus territorios lugares atractivos para la inversión pública y privada. Sin embargo, las posibilidades de lograr éxito en dicho propósito, depende en forma importante de la autonomía territorial, las capacidades endógenas y la disponibilidad de recursos.

Ahora, si entendemos la gestión urbana municipal como aquellas decisiones que desde el municipio, en forma directa o indirecta, transforman el espacio local e impactan en la calidad de vida de sus residentes y usuarios, para el caso del Área Metropolitana de Santiago de Chile existe un significativa disparidad de realidades socioterritoriales entre municipios (Orellana, 2009) que explica que, en la búsqueda de alcanzar que dichos impactos sean positivos, más que una estrategia, es por necesidad que los municipios adoptan uno u otro modelo de gestión urbana. La predominancia de un modelo de gestión por sobre otro, en muchos casos podrá ser un proceso continuo determinado, muchas veces, por la permanencia del alcalde en el cargo por ya casi dos décadas ${ }^{17}$, pero también pudiese

17 Desde el regreso de la democracia en 1990, hay va- 
ser que esa condición no sea suficiente y un mismo edil aplique en el tiempo más de un modelo.

Finalmente, en razón de los avances obtenidos a través de esta investigación y las interrogantes que se plantean, se constata la necesidad de construir un sistema de indicadores que midan la gestión urbana municipal a escala metropolitana, distinguiendo su aproximación a cada modelo. Por lo pronto, tal como se reflejara en el estudio de Fuentes et al. (2007), bajo una misma normativa que rige a los municipios metropolitanos y anclados en un país donde predomina una visión centralista y unitaria del Estado, subsisten marcadas diferencias en materia de autonomía territorial, capacidades endógenas y disponibilidad de recursos presupuestarios, cuestión que sin duda los obliga a competir entre municipios que por opción (los menos) o por inercia (la mayoría) adoptan uno u otro modelo de gestión urbana, marcando importantes diferencias de calidad de vida entre las comunas metropolitanas ${ }^{18}$.

\section{Referencias bibliográficas}

ARBÓS, X. y GINER, F. La gobernabilidad. Ciudadanía y democracia en la encrucijada mundial. Madrid: Siglo XXI, 1993.

BRESCIANI, L.E. Del conflicto a la oportunidad: Participación ciudadana en el desarroIlo urbano. En Foco, 2006, Nº 83. Disponible en Internet:

http://www.expansiva.cl/media/en_foco/ documentos/21082006093659.pdf

CAMAGNI, R. Economía Urbana. Barcelona: Antoni Bosch Editor, 2005.

CHACÓN, A. Antecedentes de la gestión municipal: las principales reformas de descentralización del régimen militar. En:

rios alcaldes de algunos municipios metropolitanos (Providencia, Pudahuel, entre otros) que a la fecha se mantienen e incluso han declarado que repostularán el año 2012 por cuatro años más.

18 Ver resultados del estudio sobre calidad de vida urbana (2011) del Núcleo de Estudios Metropolitanos (NEM), IEUT/PUC. Disponible en internet: http:// www.ieut.cl/?s=icvu\&submit. $x=14 \&$ submit. $y=6$
CRAVACUORE, D. e ISRAEL, R. (Coordinadores). Procesos políticos comparados en los municipios de Argentina y Chile (1990-2005). Buenos Aires/Santiago de Chile: Universidad Nacional de Quilmes/Universidad Autónoma de Chile, 2007.

DE MATTOS, C. Transformación de las ciudades latinoamericanas ¿Impactos de la globalización?. EURE, 2002, Vol. 28, № 85, p. 5-10.

DE MATTOS, C. y RIFFO, L. Globalización, redes, nodos y dinámica metropolitana: El Gran Santiago en los noventa. En: DE MATTOS, C.; FIGUEROA, O.; ORELLANA, A. y YÁÑEZ, G. (Editores). Gobernanza, Competitividad y Redes: La gestión en las ciudades del siglo XXI. Santiago de Chile: Colección Rideal-EURE Libros, 2005, p. 31-64.

FUENTES, L.; ALLARD, P. y ORELLANA A. El municipio y la gobernabilidad territorial. Santiago de Chile: OC-UC/EXPANSIVA/Escuela Trabajo Social UC, 2007.

HERNÁNDEZ, R.; FERNÁNDEZ, C. y BAPTISTA, P. Metodología de la Investigación. México D.F.: Mc Graw Hill, 1997.

JORDÁN, R.; SIMIONI, D. y MARTELLI, G. Guía de gestión urbana. Santiago de Chile: División de Desarrollo Sostenible y Asentamientos Humanos, CEPAL, 2003.

LE GALÉS, P. European cities: social conflicts and governance. Oxford: Oxford Financial Press, 2002.

MAYNTZ, R. New challenges to governance theory. European University Institute, Jean Monnet Chair Paper RSC No 98/50, 1998. Disponible en Internet:

http://www.uned.es/113016/docencia/spd\%20-\%20doctorado\%202001-02/ Introducci\%F3n/Mayntz\%20governance\%20 EUI\%201998.htm

MORSE, J. Qualitative significance. Qualitative Health Research, 2004, Vol. 14, No 2, p. 151-152.

MORSE, J. Evolving trends in qualitative research: advances in mixedmethod design. Qualitative Health Research, 2005, Vol. 15, No 5, p. 583-585. 
ORELLANA, A. El control social del espacio metropolitano desde lo local. En: DE MATTOS, C.; FIGUEROA, O.; ORELLANA, A. y YÁÑ̃EZ, G. (Editores). Gobernanza, Competitividad y Redes: La gestión en las ciudades del siglo XXI. Santiago de Chile: Colección Rideal-EURE Libros, 2005, p. 263-295.
ORELLANA, A. La gobernabilidad metropolitana de Santiago: la dispar relación de poder de los municipios. EURE, 2009, Vol. $35, N^{\circ} 104$, p. 101-120.

SÁNCHEZ, J.E. Espacio, economía y sociedad. Madrid: Siglo XXI, 1991. 